\title{
FIRST SUMMER SEMINAR OF THE CANADIAN MATHEMATICAL CONGRESS
}

This seminar in algebra and the theory of numbers was held at Victoria College in the University of Toronto from August 15 to September 13, 1947. The program consisted of three lecture series on research topics, four expository courses of graduate level, and subseminars with lectures on individual researches. About a hundred and thirty mathematicians took part in the seminar.

The lecture series were the following: Théorie des idéaux algèbrique, by Professor Paul Dubreil; Algebraic cohomology, by Professor Saunders MacLane; Topics from number theory, by Professor L. J. Mordell.

The expository courses were: Introductory topology, by Professor C. H. Dowker; Elementary theory of numbers, by Professors R. D. James and Gordon Pall; Introduction to modern algebra, by Professor D. C. Murdoch; Les fondements généraux des mathématiques, by Professor Adrien Pouliot.

In the sub-seminars in algebra and number theory, conducted respectively by Professors Richard Brauer and Gordon Pall, the following papers were presented:

Ernst Snapper: Linear equations in Noetherian rings.

H. S. M. Coxeter: On quadratic residues, and anallagmatic tesselations.

S. A. Jennings: Group algebras of certain infinite groups.

Christine Williams: Normal chains in groups.

R. D. James: Viggo Brun's method.

L. K. Hua: Exponential sums.

D. C. Murdoch: A theorem on nilpotent groups.

G. de B. Robinson: Nakayama's prime factor theorem.

Karl Menger: Generalization of a theorem of Minkowski.

Edward Rosenthall: The sum of cubes.

Richard Brauer: Class-number of algebraic number fields.

R. M. Thrall: Quasi-Frobenius algebras.

C. J. Nesbitt: A remark on representation of algebras.

J. S. Frame: Double coset traces.

L. K. Hua: Geometry of matrices.

R. H. Bruck: Applications of loop theory.

Grace E. Bates: Loop homomorphisms.

Irving Reiner: Meyer's theorem on primes in a binary quadratic form. L. J. Mordell: The minimum of an indefinite binary quadratic form. 
Peter Scherk: Densities.

Hans Tornehave: Generalization of Kronecker's theorem.

Leslie Peck: On a theorem of Hajos.

W. L. G. Williams: Algebraic invariants and a certain congruence.

R. D. James: Linnik's proof of the three prime theorem.

Peter Scherk: $A n$ analogue to algebraic geometry.

Harold Davenport: On a theorem of Minkowski.

Irving Kaplansky: Complete algebras.

H.S. Vandiver: On the solutions of certain general types of equations in a finite field.

A. T. Brauer: The distribution of quadratic and nth power residues. Marie-Louise Dubreil-Jacotin: On the imbedding problem.

Bjarni Jónsson: Boolean algebras.

It was decided to hold in the summer of 1949, at the time of the regular quadrennial meeting of the Congress, another seminar devoted to topics from applied mathematics and cognate fields of pure mathematics.

During the course of the month arrangements were made for the publication by the Congress of a mathematical journal. This is to be an international quarterly journal of mathematical research, the first issue appearing January 1949. The editorial board is: H. S. M. Coxeter (Editor-in-Chief), Abel Gauthier, Leopold Infeld, R. D. James, R. L. Jeffery, and G. de B. Robinson (Managing Editor).

R. ERIC O'Connor, S.J. Secretary, Canadian Mathematical Congress 